\title{
Local Therapy Modalities in Management of Colorectal Cancer Liver Metastasis
}

\author{
Yusuf Sevim, Assoc. Prof*, Ibrahim Burak Bahcecioglu, M.D, Sedat Carkit, M.D \\ Kayseri City Hospital, Department of General Surgery, Kayseri, Turkey
}

*Corresponding Author: Yusuf Sevim, Assoc. Prof., Kayseri City Hospital, Department of General Surgery, Seker Mahallesi, 38080 Molu, Kocasinan / Kayseri /Turkey, E-mail: yusufsevim@gmail.com

\begin{abstract}
Liver is the most common site of metastasis in colorectal cancers, and metastatic liver disease is found nearly $25 \%$ of the patients at diagnosis. Additionally, liver metastasis occurs in approximately half of the cases during the course of the disease. Liver metastases are important in colorectal cancer morbidity and mortality. So, management of liver metastases of colorectal cancer is important. Recently, many treatment modalities have been introduced in addition to surgery. Liver-directed therapies increase treatment options and improve outcomes in metastatic disease. In this paper, we reviewed and summarized these treatment options in patients with colorectal liver metastases.
\end{abstract}

Keywords: Colorectal cancer; liver; metastasis.

\section{INTRODUCTION}

Colorectal cancers (CRC) are the third leading cause of cancer-related mortality in both genders in the United States [1]. In 2019, an estimated 145,600 adults will be diagnosed with CRC [1]. Up to $25 \%$ of CRC admit initially with colorectal liver metastasis (CRLM), and approximately $50 \%$ develop CRLM during the course of the disease. The stage $4 \mathrm{CRC}$ has the lowest 5-year survival rates; $12 \%$ for colon cancer, $13 \%$ for rectal cancer. Liver metastasectomy may improve overall survival, and these patients may have long-term relapse free survival. So the management of liver metastasis becomes more important. The local liver therapies can expand the options of management and improve outcomes for CRLM patients.

\section{SURGERY}

There is no definite definition for resectable CRLM. Ekberg and colleagues reported traditionally resectability criteria as 4 intrahepatic metastases, no extrahepatic metastatic disease and being able to achieve at least $1 \mathrm{~cm}$ resection margin [2]. However, liver 3-dimensional reconstruction imaging technology, portal vein embolization, and associated liver partition and portal venous ligation for staged hepatectomy can increase the resectability. So, current resectability criteria are stable or resectable extrahepatic metastatic disease (excluding portal lymphadenopathy), amen able to venous resection or reconstruction, beyond $1 \mathrm{~mm}$ with a tumor-free margin, >20\% remnant liver for normal liver and slight chemotherapy-associated liver dysfunction and $>30-40 \%$ for severe chemotherapy-associated liver disease [3]. The number and distribution of liver metastasis are not decisive for resectability. Preoperative imaging procedures, such as computed tomography (CT), magnetic resonance imaging and positron emission tomography-CT are helpful to evaluate resectability. Especially $\mathrm{CT}$ is optimal to evaluate the relation between metastatic mass and vascular, biliary structures, and to identify the volume of remnant liver. Requiring resection of all hepatic veins, both portal veins, or the retrohepatic vena cava to achieve negative margins are considered unresectable, and also the resection of liver metastasis should not advised in the presence of unresectable extrahepatic disease [4].

Surgery can be performed in synchronous CRLM with 3 surgical strategies. The first is known classic or bowel first technique include removal of primary colorectal tumor, followed by chemotherapy and 3-6 months later with resection of metastatic lesion. In combined technique, resection of the primary tumor and metastatic liver lesion are performed together. The last technique is known as liver first technique and involves resection of liver 
metastasis followed by chemotherapy and removal of the primary tumor [4].

The only curative treatment option in isolated CRLM is combination of hepatic resection with systemic therapy. However, this combination is curative in only $20 \%$ of the patients, and disease recurrence primarily to the liver is occurred in approximately $70 \%$ of the patients after resection $[5,6]$.

\subsection{Biological Targeted Therapy and Chemotherapy}

Biological targeted therapy and chemotherapy are used to reduce metastatic disease in cases of unresectable CRLM and delay the progression. The chemotherapy can be administered as adjuvant or neoadjuvant for initially resectable CRLM. However there are not enough data that adjuvant chemotherapy improves overall survival [7]. In the EORTC 40983 trial, the researchers compared overall survival between perioperative chemotherapy group with leucovorin, 5-fluorouracil, and oxaliplatin (FOLFOX) and surgery alone group, and there were no statistically significant differences [8]. Data show us clinicians should avoid using preoperative chemoradiotherapy, but chemotherapy may be used to downstage CRLM for parenchymal preserving resection [9].

Combination of chemotherapy with biological agents targeting vascular endothelial growth factor (bevacizumab) or epidermal growth factor receptor (cetuximab) are recommended for unresectable CRLM in NCCN guidelines with the aim of conversion to resection [10]. The phase 2 CELIM trial evaluated cetuximab combination with FOLFOX or leucovorin, fluorouracil, and irinotecan (FOLFIRI) in unresectable CRLM and $34 \%$ of the cases included in this study achieved to undergo complete resection of liver metastasis [11]. Additionally, the phase 2 OLIVIA trial evaluated bevacizumab with modified FOLFOX-6, or leucovorin, 5-fluorouracil, oxaliplatin, and irinotecan (FOLFOXIRI) in unresectable CRLM. This study showed significantly higher overall tumor response rate, and complete resection rates in bevacizumabFOLFOXIRI group. However, grade 3 or higher adverse events such as neutropenia, diarrhea, and febrile neutropenia were seen $95 \%$ of bevacizumab-FOLFOXIRI group, and $84 \%$ of bevacizumab-mFOLFOX-6 group [12].

\subsection{Radiofrequency and Microwave Ablation}

The standard local treatment method for CRLM is resection, but oligometastatic cases can be considered for radiofrequency ablation (RFA). This is the most widely used non-surgical technique in CRLM [13]. The use RFA is a reasonable treatment option for non-surgical candidates. Shady and colleagues published the results of 162 patients with 233 CRLMs treated with RFA, and the method was found successful in $94 \%$ of the cases [14]. In this study, progression-free survival and overall survival were found 26 and 36 months respectively, and tumor size larger than $3 \mathrm{~cm}$ and more than 1 extrahepatic disease were the independent predictors of shorter overall survival [14]. Also, randomized phase 2 EORTC 40004 trial compared FOLFOX +/- bevacizumab (systemic treatment alone) and systemic treatment with RFA (combined modality), and there were no difference in overall survival initially, but prolonged follow-up showed improved overall survival in combined group. Additionally, progression-free survival was improved at 3 years in the RFA group [15]. Kwanet. al evaluated a total of 63 CRLM patients (109 tumors) treated with RFA, and they identified that average tumor-free survival was $14.4 \pm 1.4$ months (range, 1-43 months), and local recurrence was occurred in $31.2 \%$ of treated tumors (34/109) [16].

Microwave ablation is another technique for ablation that is used for particularly small metastases in CRLM. There is an ongoing prospective, randomized, phase 3 COLLISION trial comparing surgery versus ablation modality (RFA or microwave ablation) in 618 patients with $3 \mathrm{~cm}$ or less CRLM, and the primary endpoint is overall survival [17]. Ablation alone or in combination with surgical resection should be chosen in CRLM patients especially who are not optimal candidates for resection.

\subsection{Radioembolization}

Radioembolization is a minimally invasive method include both embolization and radiation therapy to treat liver cancer. The radioactive isotope yttrium 90 (Y-90) is used in this procedure. Also, this method can be named as transarterial radioembolization, internal radiation therapy, and intra-arterial brachytherapy. Generally Y-90 radioemboli zation is suggested in chemotherapy resistant or refractor cases with predominant liver metastasis (18). Radioembolization with chemot herapycan lengthen time to progression in CRLM [19]. 
The phase 3 randomized controlled SIRFLOX trial (Y-90 resin microspheres with FOLFOX+/bevacizumab vs. FOLFOX+/- bevacizumab) results showed significant prolonged progression-free survival in FOLFOX/Y-90 group (20.5 vs. 12.6 months) [20]. Additionally, the FOXFIRE and FOXFIRE Global studies showed prolonged progression-free survival similar with SIRFLOX trial [21]. Radioembolization with low systemic toxicity is a feasible treatment option for chemotherapy refractor unrespectable CRLM cases.

\subsection{Hepatic Artery Infusion Therapy}

Treatment with liver-directed chemotherapy through hepatic arterial infusion (HAI), besides systemic chemotherapy, is a method that can be used to downsize the disease in the liver with the aim of conversion to surgical resection [22]. This procedure is administered in the gastroduodenal artery by surgically implanted pump, hepatic artery port, or through a catheter connected to an external pump placed percutaneously. HAI provides less systemic toxicity. The clinicians should choose the chemotherapeutic agent for HAI in order to increase the local concentration, which increases therapeutic response and to decrease the systemic exposure. Floxuridine has short halflife and high first-pass metabolism rate, so it is the most widely used agent [23]. Also irinotecan [24] and oxaliplatin [25] have been used for intrahepatic infusion. Additionally, some investigators used irinotecan, oxaliplatin and floxuridine by HAItogether with systemic chemotherapy as first-line treatment of unresectable liver metastasis [26].

Floxuridine may cause diarrhea or gastric and duodenal ulcers because of extrahepatic profusion, and the common side effect is biliary toxicity. So that, the clinicians should monitor liver function tests every 2 weeksto adjust the dose of floxuridine [23]. Biliary toxicity of floxuridine can be decreased with combination of dexamethasone. Also using fluorouracil alternatively is a way to prevent biliary toxicity $[27,28]$.

HAI with floxuridine alone may increase the objective responses compared to systemic chemotherapy with floxuridine or 5-flourouracil [29]. Fiorentini et. Al compared HAI combination with bolus 5-flourouracil/leucovorin or HAI alone, and they identified an increase in survival in the combined group (20 vs. 14 months, $\mathrm{p}=0.0033$ ) [30].
In unrespectable CRLM, the only randomized comparison of HAI versus systemic chemotherapy is the phase 3 CALGB 9481 trial [31]. This trial showed that, improved median survival (24.4 vs. 20 months, $\mathrm{p}=0.0034)$ and objective response rate ( 47 vs. $24 \%, \mathrm{p}=0.12$ ) was associated with HAI. This trial also identified the toxicity status, and the common toxicity was biliary toxicity (Bilirubin elevation $>3 \mathrm{mg} / \mathrm{dL} ; 18.6$ vs. $0 \%, \mathrm{p}=0.006$ ). Combination of HAI with systemic chemotherapy is used to achieve conversion to complete resection of liver metastasis. In the phase 2 MSKCC trial initial report [5] and expansion cohort [32] demonstrated $47 \%$ and $52 \%$ conversion to liver metastasis respectively. Additionally adjuvant HAI after resection of CRLM has been shown to delay hepatic recurrence [33].

There are some possible complications of HAI therapy. These are hemorrhage, thrombosis, extrahepatic perfusion, incomplete perfusion as arterial complications, infection, hematoma, pump migration as pocket complications, and occlusion, dislodgement, erosion, pump malfunction as catheter complications. Also biliary sclerosis is a rare important complication associated with abnormal postoperative flow scans, postoperative infectious complications, and larger doses of floxuridine per cycle [34].

\section{CONClusion}

Improving treatment modalities in CRLM provide options to clinicians with improving clinical outcomes. Surgical resection of CRLM is curative approximately in $20 \%$ of patients, so that these local treatment modalities become more important especially in unrespectable CRLM. Some of these potentially improve overall survival or progression-free survival. More studies, clinical trials are required for unrespectable CRLM.

\section{REFERENCES}

[1] American Cancer Society. Cancer Facts \& Figures - 2018. Atlanta: American Cancer Society; 2018. www.cancer.org/ content/dam/ cancer-org/research/cancer-facts-and-statistics/ annual-cancer-facts-and-figures/2018/cancer-fa cts-and-figures-2018.pdf. Accessed November 19, 2018.

[2] Ekberg H, Tranberg KG, Andersson R, Lundstedt C, Hagerstrand I, Ranstam J, Bengmark S. Determinants of survival in liver resection for colorectal secondaries. Br J Surg 1986;73(9):727-731. 
[3] Xu F, Tang B, Jin TQ, Dai CL. Current status of surgical treatment of colorectal liver metastases. World J Clin Cases 2018;6(14):716-734.

[4] Zarour LR, Anand S, Billingsley KG, Bisson WH, Cercek A, Clarke MF, Coussens LM, Gast CE, Geltzeiler CB, Hansen L, et al. Colorectal Cancer Liver Metastasis: Evolving Paradigms and Future Directions. Cell Mol Gastroenterol Hepatol 2017;3(2):163-173.

[5] D'Angelica MI, Correa-Gallego C, Paty PB, Cercek A, Gewirtz AN, Chou JF, Capanu M, Kingham TP, Fong Y, DeMatteo RP, et al. Phase II trial of hepatic artery infusional and systemic chemotherapy for patients with unresectable hepatic metastases from colorectal cancer: conversion to resection and long-term outcomes. Ann Surg 2015;261(2):353-360.

[6] Van Cutsem E, Cervantes A, Adam R, Sobrero A, Van Krieken JH, Aderka D, Aranda Aguilar E, Bardelli A, Benson A, Bodoky G, et al. ESMO consensus guidelines for the management of patients with metastatic colorectal cancer. Ann Oncol 2016;27(8):13861422.

[7] Nishioka Y, Moriyama J, Matoba S, Kuroyanagi H, Hashimoto M, Shindoh J. Prognostic Impact of Adjuvant Chemotherapy after Hepatic Resection for Synchronous and Early Metachronous Colorectal Liver Metastases. Dig Surg 2018;35(3):187-195.

[8] Nordlinger B, Sorbye H, Glimelius B, Poston GJ, Schlag PM, Rougier P, Bechstein WO, Primrose JN, Walpole ET, Finch-Jones M, et al. Perioperative chemotherapy with FOLFOX4 and surgery versus surgery alone for resectable liver metastases from colorectal cancer (EORTC Intergroup trial 40983): a randomised controlled trial. Lancet 2008;371(9617):10071016.

[9] Mattar RE, Al-Alem F, Simoneau E, Hassanain M. Preoperative selection of patients with colorectal cancer liver metastasis for hepatic resection. World J Gastroenterol 2016;22(2):5 67-581.

[10] National Comprehensive Cancer Network. NCCN Clinical Practice Guidelines in Oncology. Colon Cancer. Version 3.2108; updated August 7, 2018. www.nccn.org. Accessed November 19, 2018.

[11] Folprecht G, Gruenberger T, Bechstein WO, Raab HR, Lordick F, Hartmann JT, Lang H, Frilling A, Stoehlmacher J, Weitz J, et al. Tumour response and secondary resectability of colorectal liver metastases following neoadjuvant chemotherapy with cetuximab: the CELIM randomised phase 2 trial. Lancet Oncol 2010;11(1):38-47.

[12] Gruenberger T, Bridgewater J, Chau I, Garcia Alfonso P, Rivoire M, Mudan S, Lasserre S,
Hermann F, Waterkamp D, Adam R. Bevacizumab plus mFOLFOX-6 or FOLFOXIRI in patients with initially unresectable liver metastases from colorectal cancer: the OLIVIA multinational randomised phase II trial. Ann Oncol 2015;26(4):702-708.

[13] Labori KJ, Schulz A, Drolsum A, Guren MG, Klow NE, Bjornbeth BA. Radiofrequency ablation of unresectable colorectal liver metastases: trends in management and outcome during a decade at a single center. Acta Radiol Open 2015;4(7):2058460115580877.

[14] Shady W, Petre EN, Gonen M, Erinjeri JP, Brown KT, Covey AM, Alago W, Durack JC, Maybody M, Brody LA, et al. Percutaneous Radiofrequency Ablation of Colorectal Cancer Liver Metastases: Factors Affecting Outcomes-A 10-year Experience at a Single Center. Radiology 2016;278(2):601-611.

[15] Ruers T, Van Coevorden F, Punt CJ, Pierie JE, Borel-Rinkes I, Ledermann JA, Poston G, Bechstein W, Lentz MA, Mauer M, et al. Local Treatment of Unresectable Colorectal Liver Metastases: Results of a Randomized Phase II Trial. J Natl Cancer Inst 2017;109(9).

[16] Kwan BY, Kielar AZ, El-Maraghi RH, Garcia LM. Retrospective review of efficacy of radiofrequency ablation for treatment of colorectal cancer liver metastases from a Canadian perspective. Can Assoc Radiol J 2014;65(1):77-85

[17] Puijk RS, Ruarus AH, Vroomen L, van Tilborg A, Scheffer HJ, Nielsen K, de Jong MC, de Vries JJJ, Zonderhuis BM, Eker HH, et al. Colorectal liver metastases: surgery versus thermal ablation (COLLISION) - a phase III single-blind prospective randomized controlled trial. BMC Cancer 2018;18(1):821.

[18] Raval M, Bande D, Pillai AK, Blaszkowsky LS, Ganguli S, Beg MS, Kalva SP. Yttrium-90 radioembolization of hepatic metastases from colorectal cancer. Front Oncol 2014;4:120.

[19] Boas FE, Bodei L, Sofocleous CT. Radioembolization of Colorectal Liver Metastases: Indications, Technique, and Outcomes. J Nucl Med 2017;58(Suppl 2):104S$111 \mathrm{~S}$.

[20] Moeslein F, Heinemann V, Sharma N, Findlay M, Ricke J, Dowling R, Price D, Gebski V, van Buskirk M, Gibbs P. SIRFLOX: Differences in site of first progression between mFOLFOX6 \pm bevacizumab (bev) versus mFOLFOX6 \pm bev+ selective internal radiation therapy (SIRT) in first-line patients (pts) with metastatic colorectal cancer (mCRC). Journal of Vascular and Interventional Radiology 2016;3(27):S7.

[21] Virdee PS, Moschandreas J, Gebski V, Love SB, Francis EA, Wasan HS, van Hazel G, Gibbs P, Sharma RA. Protocol for Combined 
Analysis of FOXFIRE, SIRFLOX, and FOXFIRE-Global Randomized Phase III Trials of Chemotherapy +/- Selective Internal Radiation Therapy as First-Line Treatment for Patients With Metastatic Colorectal Cancer. JMIR Res Protoc 2017;6(3):e43.

[22] Kemeny NE, Melendez FD, Capanu M, Paty PB, Fong Y, Schwartz LH, Jarnagin WR, Patel $\mathrm{D}$, D'Angelica M. Conversion to resectability using hepatic artery infusion plus systemic chemotherapy for the treatment of unresectable liver metastases from colorectal carcinoma. J Clin Oncol 2009;27(21):3465-3471.

[23] Zervoudakis A, Boucher T, Kemeny NE. Treatment Options in Colorectal Liver Metastases: Hepatic Arterial Infusion. Visc Med 2017;33(1):47-53.

[24] van Riel JM, van Groeningen CJ, Kedde MA, Gall H, Leisink JM, Gruia G, Pinedo HM, van der Vijgh WJ, Giaccone G. Continuous administration of irinotecan by hepatic arterial infusion: a phase I and pharmacokinetic study. Clin Cancer Res 2002;8(2):405-412.

[25] Ducreux M, Ychou M, Laplanche A, Gamelin E, Lasser P, Husseini F, Quenet F, Viret F, Jacob JH, Boige V, et al. Hepatic arterial oxaliplatin infusion plus intravenous chemotherapy in colorectal cancer with inoperable hepatic metastases: a trial of the gastrointestinal group of the Federation Nationale des Centres de Lutte Contre le Cancer. J Clin Oncol 2005;23(22):4881-4887.

[26] Chen Y, Wang X, Yan Z, Wang J, Luo J, Liu Q. Hepatic arterial infusion with irinotecan, oxaliplatin, and floxuridine plus systemic chemotherapy as first-line treatment of unresectable liver metastases from colorectal cancer. Onkologie 2012;35(9):480-484.

[27] Kemeny N, Seiter K, Niedzwiecki D, Chapman D, Sigurdson E, Cohen A, Botet J, Oderman P, Murray P. A randomized trial of intrahepatic infusion of fluorodeoxyuridine with dexamethasone versus fluorodeoxyuridine alone in the treatment of metastatic colorectal cancer. Cancer 1992;69(2):327-334.
[28] Davidson BS, Izzo F, Chase JL, DuBrow RA, Patt Y, Hohn DC, Curley SA. Alternating floxuridine and 5-fluorouracil hepatic arterial chemotherapy for colorectal liver metastases minimizes biliary toxicity. Am J Surg 1996;172(3):244-247.

[29] Arai Y, Aoyama T, Inaba Y, Okabe H, Ihaya T, Kichikawa K, Ohashi Y, Sakamoto J, Oba K, Saji S. Phase II study on hepatic arterial infusion chemotherapy using percutaneous catheter placement techniques for liver metastases from colorectal cancer (JFMC28 study). Asia Pac J Clin Oncol 2015;11(1):4148.

[30] Fiorentini G, Cantore M, Rossi S, Vaira M, Tumolo S, Dentico P, Mambrini A, Bernardeschi P, Turrisi G, Giovanis P, et al. Hepatic arterial chemotherapy in combination with systemic chemotherapy compared with hepatic arterial chemotherapy alone for liver metastases from colorectal cancer: results of a multi-centric randomized study. In Vivo 2006;20(6A):707-709.

[31] Kemeny NE, Niedzwiecki D, Hollis DR, Lenz HJ, Warren RS, Naughton MJ, Weeks JC, Sigurdson ER, Herndon JE, 2nd, Zhang C, et al. Hepatic arterial infusion versus systemic therapy for hepatic metastases from colorectal cancer: a randomized trial of efficacy, quality of life, and molecular markers (CALGB 9481). J Clin Oncol 2006;24(9):1395-1403.

[32] Pak LM, Kemeny NE, Capanu M, Chou JF, Boucher T, Cercek A, Balachandran VP, Kingham TP, Allen PJ, DeMatteo RP, et al. Prospective phase II trial of combination hepatic artery infusion and systemic chemotherapy for unresectable colorectal liver metastases: Long term results and curative potential. J Surg Oncol 2018;117(4):634-643.

[33] Kemeny NE, Chou JF, Boucher TM, Capanu M, DeMatteo RP, Jarnagin WR, Allen PJ, Fong YC, Cercek A, D'Angelica MI. Updated longterm survival for patients with metastatic colorectal cancer treated with liver resection followed by hepatic arterial infusion and systemic chemotherapy. J Surg Oncol 2016;113(5):477-484.

Citation: Yusuf Sevim, Ibrahim Burak Bahcecioglu, Sedat Carkit. Local Therapy Modalities in Management of Colorectal Cancer Liver Metastasis. ARC Journal of Surgery.2019; 5(1):27-31. DOI: http://dx.doi.org/10.2 0431/2455-572X.0501005

Copyright: (C) 2019 Authors. This is an open-access article distributed under the terms of the Creative Commons Attribution License, which permits unrestricted use, distribution, and reproduction in any medium, provided the original author and source are credited. 